International Journal of Agriculture, Environment and Bioresearch

Vol. 4, No. 05; 2019

ISSN: $2456-8643$

\title{
PHYTOCHEMICAL SCREENING OF AQUEOUS AND METHANOLIC EXTRACTS OF PHYLLANTUS AMARUS AND AZADIRACTHA INDICA LEAVES
}

\author{
Bankole, S.O, Akala, A.O, Adegboyega, D.A and Adekunle, E.A \\ Forestry Research Institute of Nigeria, Ibadan \\ http://doi.org/10.35410/IJAEB.2019.4448
}

\begin{abstract}
Bioactive phytochemical constituents in medicinal plants are sources and templates for the synthesis of new antimicrobial drugs, this study has revealed the phytochemicals present in Phyllantus amarus and Azadiractha indica. screening of the extracts of Phyllanthus amarus and Azadirachta indicawhich indicates the presence of alkaloids, flavonoids, saponins, tannins, anthraquinones, terpenoids and cardiac glycosides in varying concentrations within the aqueous and methanol extracts. Flavonoids were abundant in the crude methanolic and aqueous extract of A.indica but were absent in the methanolic and aqueous extract of P.amarus. Alkaloids were also abundantly present in the crude methanol and aqueous extract of A.indica but were significantly absent in the crude methanol and aqueous extract of P.amarus. Saponins were slightly and moderately present in the methanol and aqueous crude extract of P.amarus while it was slightly present in both the crude methanol and aqueous extract of A. indica. Tannins were not detected in the crude methanol extract of P.amarus but were moderately present in the aqueous extract while it was slightly and moderately present in the crude aqueous and methanol extract of A.indica. Anthraquinones were slightly present in the crude aqueous and methanol extract of both P.amarus and A.indica. Terpenoids were not detected in the crude methanol extract of P.amarus but was slightly detected in the crude aqueous extract and in both the crude methanol and aqueous extract of A.indica. Cardiac glycosides were absent in the crude aqueous and methanol extract of P.amarus and A.indica.
\end{abstract}

Keywords: Aqueous, Phytochemicals, Extract and Flavonoids.

\section{INTRODUCTION}

Most plants contain several compounds with antimicrobial properties for protection against aggressor agents, especially microorganisms. Active compounds found in some plants have antiseptic action; for example, thyme has thymol and carvacrol, clove has eugenol and isoeugenol, and oregano has carvacrol and terpinenol-4. In some cases, terpenes from essences that are soluble in water have higher antibacterial power than others (Knobloch et al., 1989). The plant chemicals are classified as either primary or secondary metabolites. Primary metabolites are widely distributed in nature, occurring in one form or another in virtually all organisms. In higher plants such compounds are often concentrated in seeds and vegetative storage organs and are needed for physiological development because of their role in basic cell metabolism. 
Plants generally produce many secondary metabolites which are biosynthetically derived from primary metabolites and constitute an important source of micro biocides, pesticides and many pharmaceutical drugs. From a long period of time medicinal plants or their secondary metabolites have been directly or indirectly playing an important role in the human society to combat diseases (Wink et al., 2005).

Secondary metabolites (compounds) have no apparent function in a plant's primary metabolism, but often have an ecological role, as pollinator attractants, represent chemical adaptations to environmental stresses or serve as chemical defense against micro-organisms, insects and higher predators and even other plants (allelochemics). Secondary metabolites are frequently accumulated by plants in smaller quantities than the primary metabolites (Karuppusamy, 2009; Sathishkumar and Paulsamy, 2009).

In contrast to primary metabolites, they are synthesized in specialized cell types and at distinct developmental stages, making their extraction and purification difficult. As a result, secondary metabolites that are used commercially as biologically active compounds, are generally high value-low volume products than the primary metabolites (e.g. steroids, quinines, alkaloids, terpenoids and flavonoids), which are used in drug manufacture by the pharmaceutical industries. These are generally obtained from plant materials by steam distillation or by extraction with organic or aqueous solvents and the molecular weight are generally less than 2000. Some biologically active plant compounds have found application as drug entities or as model compounds for drug synthesis and semi-synthesis.

A survey of current pharmaceutical use revealed that, of the total prescription drugs dispensed, 25\% are plant derived (Farnsworth and Morris, 1976; Ogundipe et al., 1998). Plant compounds are highly varied in structure; many are aromatic substances, most of which are phenols or their oxygen-substituted derivatives. However, there is an increased attention on extracts and biologically active compounds isolated from plant species used in herbal medicine, due to the side effects and the resistance that pathogenic micro-organisms build against the antibiotics (Essawi and Srour, 1999). New compounds inhibiting microorganisms such as benzoin and emetine have been isolated from plants (Cox, 1994). Of the various pharmaceuticals used in modern medicine, aspirin, atropine, ephedrine, digoxin, morphine, quinine, reserpine and tubocurarine serve as examples of drugs discovered through observations of indigenous medical practices (Gilani and Rahman, 2005). Eloff (1999) stated that the antimicrobial compounds from plants may inhibit bacteria by a different mechanism than the presently used antibiotics and may have clinical value in the treatment of resistant microbial strains.

Plant constituents may be isolated and used directly as therapeutic agents or as starting materials for drug synthesis or they may serve as models for pharmacologically active compounds in drug synthesis. The general research methods includes proper selection of medicinal plants, preparation of crude extracts, biological screening, detailed chemo pharmacological investigations, toxicological and clinical studies, standardization and use of active moiety as the lead molecule for drug design (Wink et al., 2005).

\subsection{Phyllanthus amarus}

Phyllanthus amarus is a plant of the family Euphorbiaceae and has about approximately 800 species which are found in tropical and subtropical countries of the world. Traditionally, Phyllanthus amarus herb has found its usefulness in the treatment of several health problems 
such as diarrhoea, dysentery, dropsy, jaundice, intermittent fevers, urinogenital disorders, scabies and wounds. Topically, it is used for several skin problems ranging from skin ulcers, sores, swelling and itchiness, wounds, bruises, scabies, ulcers and sores, edematous swellings, tubercular ulcers, ringworm, scabby and crusty lesions. Its effect in excretory system is due to its antiurolithic property and it is used in the treatment of kidney/gallstones, other kidney related problems, appendix inflammation and prostate problems( Khatoon et al., 2004; Sen and Batra, 2013; Ushie et al., 2013). The secondary metabolites present in $P$. amarus are alkaloids, flavonoids, hydrolysable tannins (Ellagitannins), major lignans, polyphenols, triterpenes, sterols and volatile oil. The main active constituents of $P$. amarus are lignans (phyllanthin, hypophyllanthin, nirurin niranthin, phyltetralin, niranthine, nirtetralin etc. (Morton, 1981; Chevallier, 2000; Srivastava et al., 2008; Kassuya et al., 2006; Huang et al., 2003; Maciel et al., 2007; Singh et al., 2009), flavonoids (Foo and Wong, 1992; Londhe et al., 2008;), ( Foo, 1995), triterpenes (phyllanthenol, phyllanthenone, phytllantheol etc.) (Maciel et al., 2007; Foo and Wong, 1992), alkaloids (Houghton et al., 1996; Kassuya et al., 2006), sterol (amarosterol-A, amarosterol-B etc.) (Ahmad and Alam, 2003) and volatile oil (linalool, phytol etc.) (Moronkola et al., 2009).

Iranloye et al (2011), investigated the aqueous leaf extract of P. amarus for analgesic and antiinflammatory activities using both thermal and chemical models of pain assessment in rats. The extract caused a significant $(p<0.05)$ dose related increased inhibition of the carrageenaninduced paw oedema in the rats. The inhibition produced by $200 \mathrm{mg} / \mathrm{kg}$ aqueous extract of P. amarus (70.20\%) was significantly higher than that of the reference drug (acetylsalicylic acid). The extract produced a marked analgesic activity by inhibiting both early and late phases of pain stimulus in formalin induced paw licking rats and also a significant and dose related increase in inhibition of the mean tail immersion duration at varying water bath temperature $(50,55$ and 60 $\left.{ }^{\circ} \mathrm{C}\right)$.

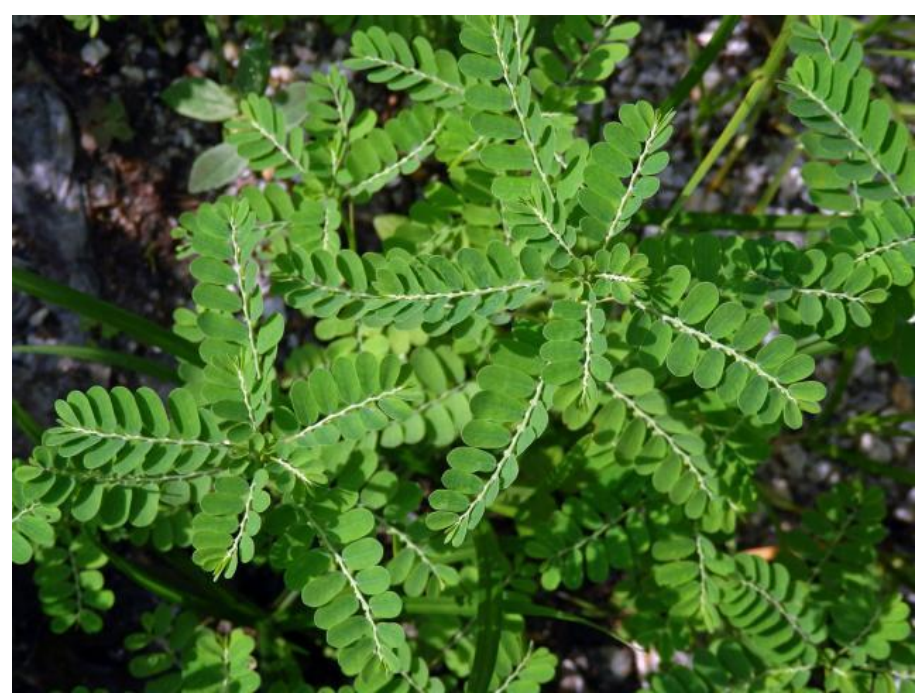

Figure 1: Phyllanthus amarus 


\section{Azadirachta indica}

Azadirachta indica is a fast growing, evergreen tree found commonly in India, Africa and America. It is a highly esteemed tree with several beneficial properties and applications, especially known for its incredible therapeutic and ethnomedicinal values for mankind.Moreover, it hasantiseptic, antifungal, antibacterial, antipyretic, anti-malaria,antidiabetic and anti-fertility properties among severalother uses (Nok et al., 1993, Natarajan et al., 2003; Fredros et al., 2007; Mbaya et al., 2010).Neem elaborates a vast array of biologically activecompounds that are chemically diverse and structurallyvariable with more than 140 compounds isolated fromdifferent parts of the tree (Subapriya and Nagini, 2005).

These compounds have been divided into two major classes: isoprenoids and others (Dev kumar and SukhDev, 1996). The isoprenoids include diterpenoids and triterpenoids containing protomeliacins, limonoids, azadirone and its derivatives, gedunin and its derivatives, vilasinin type of compounds and Csecomeliacins such as nimbin, salanin and azadirachtin. The nonisoprenoids include proteins (amino acids) and carbohydrates (polysaccharides), sulphurous compounds, polyphenolics such as flavonoids and their glycosides, dihydrochalcone, coumarin and tannins, aliphatic compounds, etc. (Kraus, 1995; Dev kumar and SukhDev, 1996).

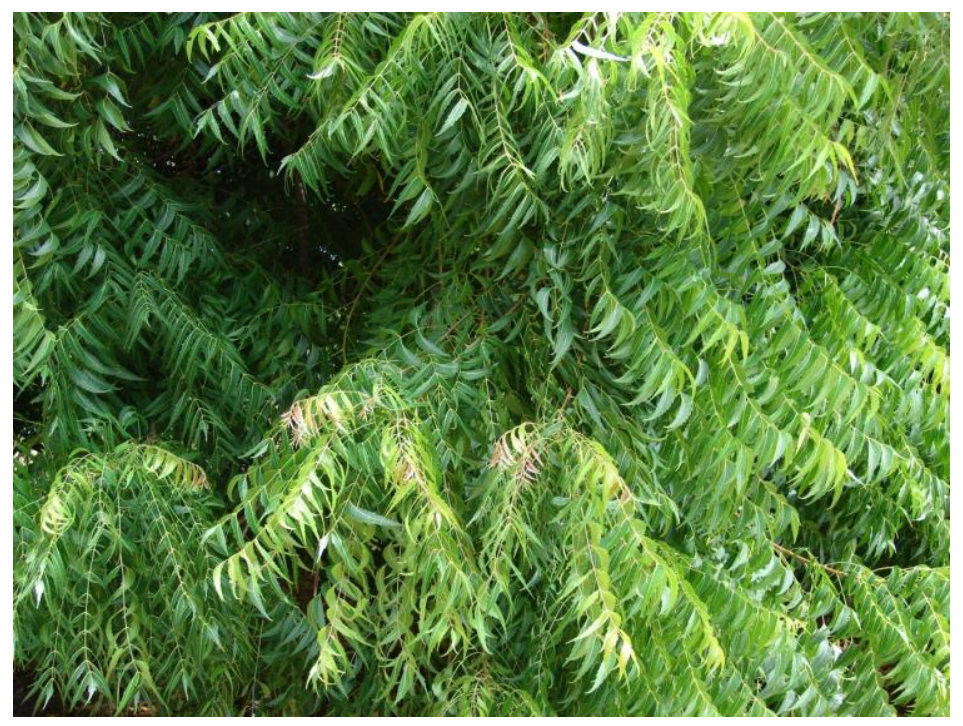

Figure 2: Azadirachta indica

2 MATERIALS AND METHODS 


\subsection{Sample Collection and Processing}

Fresh leaves of Phyllantus amarus and Azadirachta indica were collected and identified at the Forestry Research Institute of Nigeria, Oyo State, Nigeria. The leaves were washed properly to remove foreign matter and air dried. The leaves were then grinded to powder with a mechanical grinder, weighed and labeled. The powder was then subjected to various solvent extraction processes.

\subsection{Plant extraction using different solvents}

Fresh leaves of P.amarus and A.indica were dried and ground to powder. Extraction and fractionation was carried out using different solvents to determine the antimicrobial activity against the test organisms and control isolates. Extraction was achieved by cold maceration method.

\subsubsection{Extraction and Partitioning of crude extracts}

\subsubsection{Aqueous Extraction}

Three hundred and fifty grams of powdered Phyllanthus amarus and Azadirachta indica plant material was macerated via cold extraction by soaking with $1750 \mathrm{ml}$ of distilled water in flat bottomed flasks. The flasks were allowed to stand for seventy two (72) hours at room temperature with occasional stirring at intervals. The extract was filtered using a filter paper ( Whatman No.1) and the filtrate was concentrated, evaporated to dryness and weighed.

\subsubsection{Methanol Extraction}

Three hundred and fifty grams of powdered Phyllanthus amarus and Azadirachta indica plant materials was macerated via cold extraction by soaking with $1750 \mathrm{ml}$ of distilled methanol in flat bottomed flasks. The flasks were allowed to stand for seven days at room temperature with occasional stirring at intervals. The extract was filtered using a filter paper (Whatman No.1) and the filtrate was concentrated at $40^{\circ} \mathrm{C}$ under reduced pressure using rotavapor (BUCHI Rotavapor R200, Switzerland) and weighed. The crude methanol extract was dissolved in aqueous methanol in a separatory funnel and partitioned with n-hexane, ethyl acetate and chloroform. The fractions were concentrated using rotavapor, weighed and labeled. The fractions were screened for phytochemicals.

\section{Phytochemical Screening}

The medicinal and antibacterial effects of medicinal plants are mostly due to the secondary metabolites produced by them, therefore the methods described by Sofowora(1993) and Trease and Evans(1989) were used to screen the crude aqueous and methanolic extracts of P.amarus and A.indica for the presence of such metabolites. These metabolites include Alkaloids, Tannins, Saponins, Cardiac Glycosides, Flavonoids, Terpenoids and Anthraquinones.

\section{Test for anthraquinones}

$0.5 \mathrm{~g}$ of the extract was boiled with $10 \mathrm{ml}$ of sulphuric acid (H2SO4) and filtered while hot. The filtrate was shaken with $5 \mathrm{ml}$ of chloroform. The chloroform layer was pipetted into another test 
tube and $1 \mathrm{ml}$ of dilute ammonia was added. The resulting solution was observed for colour changes.

\section{Test for terpenoids (Salkowski test)}

To $0.5 \mathrm{~g}$ each of the extract was added $2 \mathrm{ml}$ of chloroform. Concentrated $\mathrm{H}_{2} \mathrm{~S} 04$ ( $3 \mathrm{ml}$ ) was carefully added to form a layer. A reddish brown colouration of the interface indicates the presence of terpenoids.

\section{Test for flavonoids}

Three methods were used to test for flavonoids. First, dilute ammonia $(5 \mathrm{ml})$ was added to a portion of an aqueous filtrate of the extract. Concentrated sulphuric acid $(1 \mathrm{ml})$ was added. A yellow colouration that disappear on standing indicates the presence of flavonoids. Second, a few drops of $1 \%$ aluminium solution were added to a portion of the filtrate. A yellow colouration indicates the presence of flavonoids. Third, a portion of the extract was heated with $10 \mathrm{ml}$ of ethyl acetate over a steam bath for $3 \mathrm{~min}$. The mixture was filtered and $4 \mathrm{ml}$ of the filtrate was shaken with $1 \mathrm{ml}$ of dilute ammonia solution. A yellow colouration indicates the presence of flavonoids.

\section{Test for saponins}

To $0.5 \mathrm{~g}$ of extract in a test tube, $5 \mathrm{ml}$ of distilled water was added. The solution was shaken vigorously and observed for a stable persistent froth. The frothing was mixed with 3 drops of olive oil and shaken vigorously after which it was observed for the formation of an emulsion.

\section{Test for tannins}

$0.5 \mathrm{~g}$ of the extract was boiled in $10 \mathrm{ml}$ of water in a test tube and then filtered. A few drops of $0.1 \%$ ferric chloride was added and observed for brownish green or a blue-black colouration

\section{Test for alkaloids}

$0.5 \mathrm{~g}$ of extract was diluted to $10 \mathrm{ml}$ with acid alcohol, boiled and filtered. To $5 \mathrm{ml}$ of the filtrate was added $2 \mathrm{ml}$ of dilute ammonia. $5 \mathrm{ml}$ of chloroform was added and shaken gently to extract the alkaloidal base. The chloroform layer was extracted with $10 \mathrm{ml}$ of acetic acid. This was divided into two portions. Mayer's reagent was added to one portion and Draggendorff's reagent to the other. The formation of a cream (with Mayer's reagent) or reddish brown precipitate (with Draggendorff's reagent) was regarded as positive for the presence of alkaloids.

\section{Test for cardiac glycosides (Keller-Killiani test)}

To $0.5 \mathrm{~g}$ of extract diluted to $5 \mathrm{ml}$ in water was added $2 \mathrm{ml}$ of glacial acetic acid containing one drop of ferric chloride solution. This was underlayed with $1 \mathrm{ml}$ of concentrated sulphuric acid. A brown ring at the interface indicated the presence of a deoxysugar characteristic of cardenolides. A violet ring may appear below the brown ring, while in the acetic acid layer a greenish ring may form just above the brown ring and gradually spread throughout this layer.

\section{RESULTS}

\subsection{Phytochemical Screening}


Table 3.1 shows the result of the qualitative phytochemical screening of the extracts of Phyllanthus amarus and Azadirachta indicawhich indicates the presence of alkaloids, flavonoids, saponins, tannins, anthraquinones, terpenoids and cardiac glycosides in varying concentrations within the aqueous and methanol extracts. Flavonoids were abundant in the crude methanolic and aqueous extract of A.indica but were absent in the methanolic and aqueous extract of P.amarus. Alkaloids were also abundantly present in the crude methanol and aqueous extract of A.indica but were significantly absent in the crude methanol and aqueous extract of P.amarus. Saponins were slightly and moderately present in the methanol and aqueous crude extract of P.amarus while it was slighltly present in both the crude methanol and aqueous extract of $A$. indica. Tannins were not detected in the crude methanol extract of P.amarus but were moderately present in the aqueous extract while it was slightly and moderately present in the crude aqueous and methanol extract of A.indica. Anthraquinones were slightly present in the crude aqueous and methanol extract of both P.amarus and A.indica. Terpenoids were not detected in the crude methanol extract of P.amarus but was slightly detected in the crude aqueous extract and in both the crude methanol and aqueous extract of A.indica. Cardiac glycosides were absent in the crude aqueous and methanol extract of P.amarus and A.indica.

Table 3.1: Phytochemical Screening of P.amarus And A.indica Extracts

\begin{tabular}{|c|c|c|c|c|}
\hline Constituents & $\begin{array}{l}\text { P.amarus } \\
\text { Methanolic } \\
\text { crude extract }\end{array}$ & $\begin{array}{l}\text { P.amarus } \\
\text { Aqueous crude } \\
\text { extract }\end{array}$ & $\begin{array}{l}\text { A.indica } \\
\text { Methanolic } \\
\text { crude extract }\end{array}$ & $\begin{array}{l}\text { A.indica } \\
\text { Aqueous crude } \\
\text { extract }\end{array}$ \\
\hline Alkaloids & - & - & +++ & +++ \\
\hline Flavonoids & - & - & +++ & +++ \\
\hline Saponins & + & ++ & + & + \\
\hline Tannins & _ & ++ & + & ++ \\
\hline Anthraquinones & + & + & + & + \\
\hline
\end{tabular}




\begin{tabular}{|c|c|c|c|c|}
\hline Terpenoids & - & + & + & + \\
\hline $\begin{array}{l}\text { Cardiac } \\
\text { Glycosides }\end{array}$ & - & - & - & - \\
\hline
\end{tabular}

\section{DISCUSSION}

The phytochemical analysis of plants examines the presence of phytochemicals considered as active medicinal chemical constituents. This study revealed the presence of bioactive constituents present in Pyhllanthus amarus and Azadirachta indica. The qualitative analysis of the aqueous and methanol extracts of both plants showed the varying presence of Alkaloids, Flavonoids, Saponins, Tannins, Anthraquinones, Terpenoids, and Cardiac Glycosides. Alkaloids, Flavonoids and Cardiac Glycosides were absent in both the aqueous and methanol extract of Phyllanthus amarus. Tannins and Terpenoids were also absent in the methanolic extract of Phyllanthus amarus but were found to be present in the aqueous extract. However, the results showed that Alkaloids and Flavonoids were abundantly present in both the aqueous and methanol extract of Azadirachta indica which is similar to the work of. Cardiac Glycosides were found to be absent in both the aqueous and methanol extract of Azadirachta indica. The results also showed that the different solvents; ethyl acetate, chloroform, n-hexane used for fractionation possess considerable amounts of bioactive compounds.

\section{CONCLUSION}

Azadirachta indica has become important in the global context today because it offers answers to the major concerns facing mankind. It is a fast-growing evergreen popular tree found commonly in India, Africa and America. As recorded in Table 1, methanolic extract of A. indica shows the presence of glycoside having highest concentration, while alkaloids, flavonoids, tannins and sugar having moderate concentration and saponins having low concentration. At the same time, in aqueous extract was found to have maximum number of phytoconstituents in saponins and flavonoid, sugar have low concentration. The Medicinal plants are rich in secondary metabolites which include alkaloids, flavonoids, saponins and related active metabolites which are of great medicinal value and have been extensively used in the drug and pharmaceutical industry. These secondary metabolites are reported to have many biological and therapeutic properties. Recently number of studies had been reported on the phytochemistry of medicinal plants, particularly on the vegetative parts like leaves and stems etc. Alkaloids, flavonoids, glycosides have been reported to exert multiple biological effects like anti-inflammatory, anti-allergic, antioxidant, anti-diabetic, anti-viral and anti-cancer activities, anti-leprosy activities, antimicrobial activity etc. The phytoconstituents are well known for its curative activity against several human problems such as ulcers, swollen liver, malaria, dysentery, diarrhea etc. A variety of herbs and herbal extracts contain different phytochemicals with biological action that can be of valuable 
therapeutic index. Much of the protective effect of herbal plants has been attributed by phytochemicals, which are the non-nutrient compounds.

\section{REFERENCES}

Ahmad, B., Alam, T., 2003. Components from whole plant of Phyllanthus amarus Linn.

Indian Journal of Chemistry, Section B: Organic Chemistry including Medicinal Chemistry 42, $1786-1790$.

.Chevallier, A., 2000. Encyclopedia of Herbal Medicine: Natural Health, Second ed. Dorling Kindersley Book, USA, 336 p.

Clinical and Laboratory StandardsInstitute (CLSI) (2011).Performance standards for antimicrobial susceptibilitytesting: Twenty-first Informational Supplement, Vol. 31No.1PA USA, CLSI: Wayne; M100-21.

Dev kumar, C. and SukhDev. 1996, in Neem (eds Randhawa and Parmar, B. S.), , 2nd edn, pp. $77-110$.

Elavarasu, S., P. Abinaya, S. Elanchezhiyan, Thangakumaran, K. Vennila and K.B. Naziya, 2012. Evaluation of anti-plaque microbial activity of Azadirachta indica (neem oil) in vitro: A pilot study. J. Pharm. Bioallied Sci., 4: S394-S396.

Evi PL, Degbeku K. Antidiabetic Activity of Phyllanthusamarus Schum and Thonn on Alloxan induced diabetes inMale Wistar Rats. Journal of Applied Sciences 2011;11(16):2968-2973.

Foo, L.Y., 1995. Amarinic acid and related ellagitannins from Phyllanthus amarus. Phytochemistry 39, 217-224.

Foo, L.Y., Wong, H., 1992. Phyllanthusiin D, an unusual hydrolysable tannin from Phyllanthus amarus. Phytochemistry 31, 711-713.

Harjai, K., A. Bala, R.K. Gupta and R. Sharma, 2013. Leaf extract of Azadirachta indica (Neem): A potential antibiofilm agent for Pseudomonas aeruginosa. Pathogens Dis., 69: 62- 65 Hill AF. Economic Botany: A Text Book of Useful Plants and Plant Products. 2nd Edn. New York: McGraw Hill Book Company, Inc.; 1989.

Houghton, P.J., Woldemariama, T.Z., Siobhan, O.S., Thyagarajan, S.P., 1996. Two securinega type alkaloids from Phyllanthus amarus. Phytochemistry 43, 715-717.

Huang, R.L., Huang, Y.L., Ou, J.C., Chen, C.C., Hsu, F.L., Chang, C., 2003. Screening of 25 compounds isolated from Phyllanthus Species for anti-human hepatitis B virus in vitro. Phytotherapy Research 17, 449-453.

Kassuya, C.A., Silvestre, A., Menezes-de-Lima Jr., O., Marotta, D.M., Rehder, V.L. Calixto, J.B., 2006. Antiinflammatory and antiallodynic actions of the lignin niranthin isolated from 
Phyllanthus amarus. Evidence for interaction withplatelet activating factor receptor,European Journal of Pharmacology 546,182-188.

Knobloch K, Pauli A, Iberl B. 1989 Antibacterial and antifungal properties of essential oil components. J Essent Oil Res.;1(3):119-28.

Khatoon S, Rai V, Rawat A. 2004 Comparative pharmacognostic studies of three Phyllanthus species. Journal of Ethnopharmacology; 104:79-86.

Kraus, W. (1995), in The Neem Tree: Source of Unique Natural Products for Integrated Pest

Management, Medicine, Industry and Other Purposes (ed. Schmutterer, H.), pp 35-88. .

Maciel, M.A.M., Cunha, A., Dantas, F.T.N.C., Kaiser, C.R., 2007. NMR characterization of bioactive lignans from Phyllanthus amarus Schum \& Thonn. Journal of Magnetic Resonance Imaging 6, 76-82.

Maragathavalli, S., S. Brindha, N.S. Kaviyarasi, B. Annadurai and S.K. Gangwar, 2012. Antimicrobial activity in leaf extract of Neem (Azadirachta indica Linn.). Int. J. Sci. Nat.,3: 110113

Mbaya, W.A., U.I. Ibrahim, O. Thank God and L. Sanya, 2010. Toxicity and potential antitrypanosomal activity of ethanolic extract ofAzadirachta indica (Maliacea) stem bark: an in vivo and in vitro approach using Trypanosoma brucei. J. Ethnopharm., 128: 495-500

Mehrotra, S., A.K. Srivastava and S.P. Nandi, 2010. Comparative antimicrobial activities of Neem, Amla, Aloe, Assam tea and Clove extracts against Vibrio cholerae, Staphylococcus aureus and Pseudomonas aeruginosa. J. Med. Plants Res., 4: 2473-2478.

Moronkola, D.O., Ogunwande, I.A., Oyewole, I.O., Baser, K.H.C., Ozek, T., Ozek, G.,

2009. Studies on the volatile oils of Momordica charantia L. (Cucurbitaceae) and Phyllanthus amarus Sch.et Thonn (Euphorbiaceae). Journal of Essential Oil Research 21, 393-399

Morton, J.F., 1981. Atlas of Medicinal Plants of Middle America. Library of Congress Cataloging in Publication Data. Thomas books, 1420 p.

Natarajan, V., V.P. Venugopal and T. Menon, 2003. Effect of Azadirachta Indica on the growth pattern of dermatophytes. Ind. J. Med.Microbiol., 21: 98-101

Nok, A.J., E. Kan, I. Hongdet, S. Arowosafe, C.P. Onyenekwe , E.C. Gimbaand A.J. Kagbu, 1993. Trypanocodal Potentials of Azadichracta indica: In vivo activity of leaf extract against T.b. brucei. J. Clin.Biochem. Nutr., 15: 113-118

Prashant, G.M., G.N. Chandu, K.S. Murulikrishna and M.D. Shafiulla, 2007. The effect of mango and Neem extract on four organisms causing dental caries: Streptococcus mutans, Streptococcus salivarius, Streptococcus mitis and Streptococcus sanguis: An in vitro study. Indian J. Dent. Res., 18: 148-151. 
Romero, C,D., S.E. Choph, G. Buck, E. Martinez, M.Garcia, and L. Bixby. 2005. Antibacterial properties of common herbal remedies of thesouthwest. J. Ethnopharmacol. 99:253-257.

Rosaline, H., D. Kandaswamy, D. Gogulnath and M. Rubin, 2013. Influence of various herbal irrigants as a final rinse on the adherence ofEnterococcus faecalis by fluorescence confocal laser scanning microscope. J. Conserv. Dent., 16: 352-355.

SaiRam, M., G. Ilavazhagan, S.K. Sharma, S.A. Dhanraj and B. Suresh et al., 2000. Antimicrobial activity of a new vaginal contraceptive NIM-76 from Neem oil (Azadirachta indica). J. Ethnophamacol., 71: 377-382.

Saradhajyothi Koona, Subbarao Budida (2011) Antimicrobial potential of the extracts of the leave of Azadirachta indica, Linn. Nat Sci Biol, 3(1) 65-69.

Sarmiento, W.C., C.C. Maramba and M.L.M. Gonzales, 2011. An in-vitro study on the antibacterial effect of Neem (Azadirachta indica) leaf extract on methicillin-sensitive and Methicillin-resistant Staphylococcus aureus. PIDSP J., 12: 40-45.

Sen A, Batra A. (2013) The study of in vitro and in vivoantioxidant activity and total phenolic content of Phyllanthus amarus Schum Thonn: A medicinally importantplant. International Journal of Pharmacy and PharmaceuticalSciences 5:947.

Shravan K.D., Ramakrishna R., Santhosh K.M., Kannappan N. (2011), In vivo Antidiabetic evaluation of Neem leaf extract in alloxan induced rats, Journal of Applied Pharmaceutical Science.,1(4), 100-105

Singh, M., Tiwari, N., Shanker, K., Verma, R.K., Gupta, A.K., Gupta, M.M., 2009. Two new lignans from Phyllanthus amarus. Journal of Asian Natural Products Research 11, 562-568

Srivastava, V., Singh, M., Malasoni, R., Shanker, K., Verma, R.K., Gupta, M.M., Gupta, A.K., Khanuja, S.P.S., 2008. Separation and quantification of lignans in Phyllanthus species by a simple chiral densitometric method. Journal of Separation Science 31, 2338.

Stuart B and Bonnie M (2004).Antibacterial resistance worldwide:causes, challenges and responses.Nature Medicine., 10: 122-129.

Subapriya. R. and Nagini. S, 2005. Medicinal properties of neem leaves: areview. Curr. Med. Chem. Anticancer Agents, 5: 149-160

Ushie O, Neji P, Etim E. (2013) Phytochemical screening andantimicrobial activities of Phyllanthus amarus stem barkextracts. International Journal of Modern Biology and Medicines 3:101-112.

Vinothkumar, T.S., M.I. Rubin, L. Balaji and D. Kandaswamy, 2013. In vitro evaluation of five different herbal extracts as an antimicrobial endodontic irrigant using real time quantitative polymerase chain reaction. J. Conserv. Dent., 16: 167-170. 